\title{
The PDE4 Inhibitor HT-07I 2 Improves Hippocampus-Dependent Memory in Aged Mice
}

\author{
Marco Peters*,', Matthew Bletsch',2, Jennifer Stanley', Damian Wheeler', Roderick Scott' and Tim Tully' \\ 'Dart Neuroscience, LLC, San Diego, CA, USA
}

\begin{abstract}
Aging is associated with declines in memory and cognitive function. Here, we evaluate the effects of $\mathrm{HT}-07 / 2$ on memory formation and on CAMP response element-binding protein (CREB)-regulated genes in aged mice. HT-07/2 enhanced long-term memory formation in normal young mice at brain concentrations similar to those found to increase CRE-mediated gene expression in hippocampal neurons. Aged mice showed significantly poorer contextual and trace conditioning compared with young-adult mice. In aged mice, a single injection of HT-07/2 significantly boosted contextual and trace long-term memory. Additional effects of HT-07/2 were seen in a spatial memory task. Our parallel biochemical experiments revealed that inductions of the CREB-regulated genes, cFos, Zif268, and Bdnf, after fear conditioning were diminished in aged mice. HT-07/2 facilitated expression of these CREB-regulated genes in aged hippocampus, indicating that the drug engages a CREB-regulated mechanism in vivo. These findings corroborate and extend our previous results on the mechanism of action of HT-07/2 and its efficacy to enhance memory formation. Our data also indicate that HT-07/2 may be effective to treat age-associated memory impairment in humans.
\end{abstract}

Neuropsychopharmacology (2014) 39, 2938-2948; doi:I0.1038/npp.2014.154; published online 30 July 2014

\section{INTRODUCTION}

Aging is associated with robust declines in episodic memory (Hedden and Gabrieli, 2004). Age-associated memory impairment (AAMI) is common in the elderly. Amnestic mild cognitive impairment (MCI) occurs in 3 to $19 \%$ of those older than 65 years of age, with some individuals remaining stable over time, but more than half progressing to dementia within 5 years (Simon et al, 2012). With an aging population, AAMI and MCI will impact the quality of life of many millions of people. With no treatments available, age-related memory impairment and cognitive decline represents a large unmet clinical need.

In rodents, aging impairs memory formation in several hippocampal tasks, including contextual, spatial and temporal memory (Rapp et al, 1987; Barnes, 1988; Gallagher and Pelleymounter, 1988; Bach et al, 1999; McEchron et al, 2004; Fukushima et al, 2008). Memory consolidation of such declarative tasks requires cAMP response element-binding protein (CREB), a transcription factor regulating the expression of a large number of plasticity-associated genes (Bourtchuladze et al, 1994; Peters et al, 2009; Lonze and Ginty, 2002). Previous studies have suggested that enhancing CREB function via increas-

*Correspondence: Dr M Peters, Vertebrate Neurobiology, Dart Neuroscience, LLC, 12278 Scripps Summit Drive, San Diego, CA 92131, USA, Tel: + | 619 8587363067, Fax: + | 6198587363056 ,

E-mail:mpeters@dartneuroscience.com

${ }^{2}$ Current address: NBTY, Inc., Ronkonkoma, NY I 1779, USA.

Received 28 January 20 I 4; revised 6 June 20 I 4; accepted 17 June 20 I4; accepted article preview online 26 June 2014 ing cAMP signaling may provide a treatment for memory deficits in aged animals. Rolipram, a prototypical phosphodiesterase 4 (PDE4) inhibitor, has been shown to enhance spatial and contextual memory in aged mice and rats (Barad et al, 1998; Bach et al, 1999; Monti et al, 2006). Rolipram facilitates CREB function, and several studies support the idea that impaired CREB function contributes to age-related memory impairment. For example, age-impaired rats have reduced levels of CREB protein in hippocampus, whereas such CREB levels are normal in age-unimpaired or young rats (Brightwell et al, 2004). Activation of CREB by Ser133 phosphorylation and expression of the CREBregulated gene, $\mathrm{C} / \mathrm{EBP} \beta$, in hippocampus are reduced after context conditioning in aged rats (Monti et al, 2005). Importantly, overexpression of CREB in hippocampus attenuates memory deficits in aged rats (Mouravlev et al, 2006).

Together, these studies have indicated that enhancing CREB function via PDE4 inhibition may provide a suitable strategy to treat age-related memory deficits (Barad et al, 1998; Bach et al, 1999; Tully et al, 2003). Because Rolipram produces unwanted side effects (including emesis), attention has turned to developing new PDE4 inhibitors with more favorable side effect profiles (Tully et al, 2003). One such PDE4 inhibitor, HT-0712, facilitates expression of a CRE-luciferase reporter gene and expression of the CREB target-gene somatostatin in SK-N-MC neuroblastoma cells. HT-0712 also ameliorates memory deficits in a mouse model of Rubinstein-Taybi syndrome, and motor deficits in a rat model of stroke (Bourtchouladze et al, 2003; MacDonald et al, 2007). 
Here, we show that HT-0712 potently enhances memory in both young and old mice. Interestingly, we found that the induction of CREB-regulated genes after fear conditioning training was reduced in aged animals. Importantly, HT-0712 enhanced CRE-mediated gene expression in vitro and augmented the training-induced expression of CREBregulated genes in hippocampus of aged animals. Together, our data support a model in which HT-0712 ameliorates memory impairment via inhibition of PDE4, elevation of cAMP and enhancement of CRE-mediated gene expression. We therefore suggest that PDE4 inhibition may provide a much needed treatment for AAMI in humans.

\section{MATERIALS AND METHODS}

\section{Animals and Environment}

We used young-adult (3-month old) C57BL/6 male mice (Taconic, NY) and aged mice (20 \pm 1 -month old) for biochemistry, trace and delay conditioning, and MWM testing. $24 \pm 1$-month old mice were used for context conditioning. Upon arrival, mice were group-housed (five mice) in standard laboratory cages and maintained on a 12:12 h light-dark cycle. The experiments were always conducted during the light phase of the cycle. The day before the initiation of the experiment, mice were single housed in individual cages and maintained so till the end of the experiment. With the exception of training and testing times, the mice had ad libitum access to food and water. Mice were maintained under standard conditions consistent with NIH guidelines, and studies were approved by the Dart Neuroscience Institutional Animal Care and Use Committee.

\section{Drug Compound Administration}

HT-0712 was freshly prepared from a stock solution $(10 \mathrm{mg} /$ $\mathrm{ml}$ DMSO), which was maintained at $4{ }^{\circ} \mathrm{C}$. The compound was dissolved in 1\% DMSO/PBS and administered intraperitonially (i.p.) in a volume of $8 \mathrm{ml} / \mathrm{kg} 20 \mathrm{~min}$ before training. Control animals received vehicle alone (1\% DMSO/PBS). To test oral bioavailability, HT-0712 was dosed in $0.3 \mathrm{ml}$ at 30 min before training (vehicle: $2 \%$ DMSO and $98 \%$ CMC). Drug levels in blood, plasma, and brain were determined by mass spectrometry at $60 \mathrm{~min}$ after oral dosing to determine drug exposure during behavior training (Figure 1a). An experimentally naive group of animals was used for each training and drug-injecting procedure.

\section{Fear Conditioning}

To assess contextual memory, we used a standardized contextual fear conditioning ( $\mathrm{CFC}$ ) task (Bourtchuladze et al, 1994). On the training day, the mouse was placed into the conditioning chamber (Med Associates, VA) for $2 \mathrm{~min}$ before the onset of the unconditioned stimulus (US), a $0.5 \mathrm{~mA}$ footshock of $2 \mathrm{~s}$ duration. The US was repeated five times with a 1 min inter-trial interval between shocks. After the last training trial, the mice were left in the conditioning chamber for another $30 \mathrm{~s}$ and were then placed back in their home cages. Contextual memory was tested $30 \mathrm{~min}$ (STM) or $24 \mathrm{~h}$ (LTM) later in training chamber and conditioning was assessed by scoring freezing behavior for $3 \mathrm{~min}$. For delay and trace conditioning, the mouse was placed in the conditioning chamber (Med Associates) for $2 \mathrm{~min}$ before the onset of the conditioned stimulus (CS), a tone, which lasted for $20 \mathrm{~s}$ at $2800 \mathrm{~Hz}, 85 \mathrm{~dB}$. In auditory delay conditioning experiments, the US coincided with the last $2 \mathrm{~s}$ of the CS. In auditory trace conditioning experiments, an interval of $15 \mathrm{~s}$ was imposed between the offset of the CS and the onset of the US. After an additional $30 \mathrm{~s}$ in the chamber, the mouse was returned to its home-cage, and then tested 1 day later in a novel chamber (a modified home-cage). Each test began with $2 \mathrm{~min}$ of light only (preCS), then $20 \mathrm{~s}$ of tone presentation (CS), followed by an additional $30 \mathrm{~s}$ of light only. The proceeding of each experiment was filmed, and the experimenter was kept blind to drug treatment.

\section{Morris Water Maze Testing}

Spatial reference memory in the MWM was determined as previously described (Bourtchuladze et al, 1994). We used a $1.2 \mathrm{~m}$ pool and the platform was $8 \mathrm{~cm}$ in diameter. Aged C57Bl/6Tac mice were trained with four trials per day (trial length $60 \mathrm{~s}, 1 \mathrm{~min}$ ITI) for 5 days per week, with a 2-day break between weeks 1, 2 and 3. Sixty-second probe trials were given at the end of training days 3, 5, 10, and, 15. Mice were dosed with HT- 0712 or vehicle via i.p. injection $20 \mathrm{~min}$ prior to the first trial on each training day.

\section{Nociception Test}

Response threshold was determined to exclude confounding effects of drug treatment on shock perception in fear conditioning (Barad et al, 1998; Bourtchuladze et al, 1994). C57BL/6 mice were injected i.p. with $0.1 \mathrm{mg} / \mathrm{kg}$ HT-0712, placed in a conditioning chamber, and subjected to $1 \mathrm{~s}$ shocks of gradually increasing amperage $(0.1,0.25,0.35$, $0.45,0.55,0.65$, and $0.75 \mathrm{~mA}$ ). The interval between shocks was $10 \mathrm{~s}$. Mice were scored for their first visible response to the shock (flinch), their first extreme motor response (run/jump), and their first vocalized distress.

\section{Open Field}

The experiments were performed similar to those described previously (Barad et al, 1998). Male C57BL/6 mice were treated with drug or vehicle control and exploration observed in a standard open field using a computerized tracking system (EthoVision by Noldus, VA). Two boxes were run simultaneously and animals were scored for distance traveled (horizontal activity) and rearing (vertical activity). Distance and rearing frequency were measured for $20 \mathrm{~min}$ and averaged in $5 \mathrm{~min}$ intervals.

\section{Enzymatic Assays and Binding Studies}

Inhibition of full-length PDE4d3, PDE1b, PDE2a, PDE3a, and PDE10a enzymes was tested using the IMAP TR-FRET cAMP assay (Molecular Devices). The assays were performed in 1536-well white plates. Briefly, PDE enzyme was dispensed in IMAP assay buffer consisting of $10 \mathrm{mM}$ Tris $\mathrm{pH} 7.2,10 \mathrm{mM} \mathrm{MgCl} 2,1 \mathrm{mM} \mathrm{DTT}$, and $0.1 \%$ fatty acid-free BSA. The test compound was then added from $1 \mathrm{mM}$ stocks in DMSO using a Kalypsys Pintool. Plates were incubated 
a

\begin{tabular}{|c|c|c|c|c|c|}
\hline $\begin{array}{c}\text { Dose } \\
\text { (p.o.) }\end{array}$ & time & $\begin{array}{c}\text { Plasma } \\
(\mathrm{ng} / \mathrm{ml})\end{array}$ & $\begin{array}{c}\text { Brain } \\
(\mathrm{ng} / \mathrm{g})\end{array}$ & $\begin{array}{c}\text { Brain } \\
(\mathrm{nM})\end{array}$ & B/P ratio \\
\hline $1 \mathrm{mg} / \mathrm{kg}$ & $1 \mathrm{hr}$ & 11 & 13 & 34 & 1.2 \\
\hline $10 \mathrm{mg} / \mathrm{kg}$ & $1 \mathrm{hr}$ & 158 & 170 & 433 & 1.1 \\
\hline
\end{tabular}

b<smiles>COc1ccc([C@H]2CNC(=O)[C@H](Cc3cccc(C)c3)C2)cc1OC1CCCC1</smiles>

C
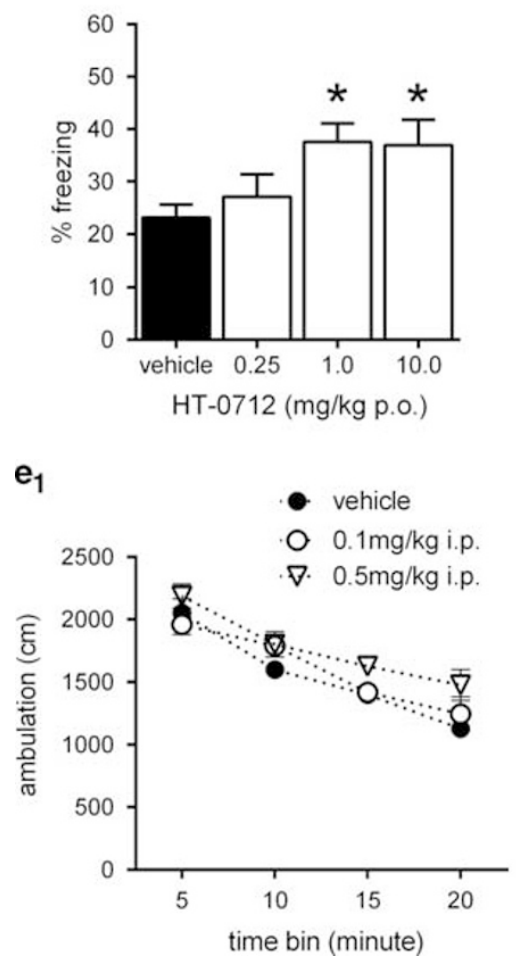
d $2 x$ trials $5 x$ trials

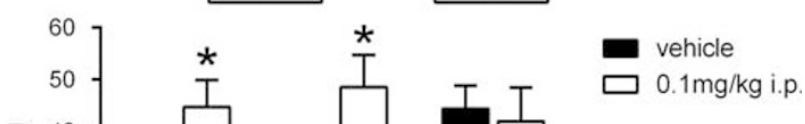

Figure I HT-07/2 facilitates memory formation in young mice. Drug exposure and memory-enhancing properties of HT-07/2 in young mice. (a) Brain and plasma concentrations of HT-07/2 I h after oral (p.o.) dosing in C57B//6 mice. (b) Structure of HT-07/2. (c) Effect of HT-07/2 dosed p.o. at I mg/kg and $10 \mathrm{mg} / \mathrm{kg}$ on contextual freezing in the mouse. Vehicle: $n=44,0.25 \mathrm{mg} / \mathrm{kg}: \mathrm{n}=22,1 \mathrm{mg} / \mathrm{kg}: \mathrm{n}=34,10 \mathrm{mg} / \mathrm{kg}: n=16$. (d) Effect of HT-07 I2 dosed i.p. at $0.1 \mathrm{mg} / \mathrm{kg}$ on contextual memory. HT-07/2 dosed 20 min prior or $60 \mathrm{~min}$ after two trial training significantly enhanced 4-day memory. No drug effect was observed if mice were trained with five trials. Vehicle: $n=8, H T-07 \mid 2: n=8$. (e) Open-field exploratory behavior in mice dosed with HT-07|2 (i.p.) or vehicle control. The distance traveled and rearing frequency were measured for 20 min and averaged in 5 min intervals. HT-07/2 did not produce any significant changes in total distance traveled $\left(e_{1}\right)$ or rearing frequency $\left(e_{2}\right)$ compared with vehicle-injected $C 57 B L / 6$ mice. Vehicle: $n=8, H T-07 / 2: n=8$. Mean \pm SEM are shown. Significant differences from vehicle control are indicated by an asterisk (*).

for $5 \mathrm{~min}$ at room temperature before dispensing $533 \mathrm{nM}$ FAM-cAMP substrate for a final concentration of $200 \mathrm{nM}$. Following a brief centrifugation, plates were incubated for $30 \mathrm{~min}$ at room temperature. The assay was terminated by adding IMAP-binding reagent $\mathrm{Tb}$ complex to each well, which was prepared according to manufacturer's recommendations (Molecular Devices). Plates were incubated for an additional $90 \mathrm{~min}$ at room temperature and read on a Viewlux plate reader. All compounds were tested in 11-point half-log dose-responses. Curve fitting and IC50 values were determined using a standard four parameter fit. Selectivity profiling against a panel of 60 GPCRs, ligandgated ion channels, and neurotransmitter transporters expressed in the CNS was performed by CEREP (Poitiers,
France). Percentages of specific binding of reference ligands to the targets of interest were determined in the presence of HT-0712 $(10 \mu \mathrm{M})$ or vehicle. For each assay, a respective reference compound was tested concurrently with HT-0712.

\section{Quantitative Real-Time PCR}

C57BL/6 mice were trained in trace fear conditioning ( $\mathrm{tFC}$ ) (15 s trace interval). Sixty-minutes after training, the animals were killed by cervical dislocation, and hippocampi were isolated. Naive animals (taken from the home-cage) were used as control. Five animals were trained per condition. Their hippocampi were kept frozen at $-80{ }^{\circ} \mathrm{C}$ until RNA extraction. RNA was isolated using the QIAgen 
RNeasy kit (Qiagen) according to the manufacturer's specifications. cDNA was generated using TaqMan Reverse transcriptase kit (Applied Biosystems). Real-time PCR was performed using the ABI prism $7900 \mathrm{HT}$ sequence detection system (Applied Biosystems) and SDS 2.1 software. We used ABI assays for $c F o s, B d n f$, Ngfi-b, and Tbp (Applied Biosystems). Our assay for $B d n f$ was specific to the CREBregulated exon 1 promoter (Lonze and Ginty, 2002). We found that $B d n f 1$ was more prominently induced by tFC in mice. Similar effects as shown here were observed for $B d n f$ exon 4. Real-time PCR reactions were run in duplicate and the CT values averaged. Data were normalized to TATA binding protein $(T b p)$ and $\Delta C T$ values were determined as a percentage change from young naive animals. Each experiment was repeated at least once with similar results.

\section{Neuronal Culture and Assessment of CRE-Mediated Gene Expression}

Hippocampi from E17.5 mouse embryos were dissociated in papain and plated on poly-D-lysine coated 96-well plates (BD Biosciences). Cultures were maintained in NbActiv4defined medium (BrainBits, LLC) for 7-10 days. We then transduced our cultures with Adenovirus containing a dual reporter construct. Firefly luciferase was expressed from a minimal CMV promoter containing CRE-sites to assess drug effects on CRE-mediated gene expression. Renila luciferase was expressed from a U6 promoter to control for nonspecific drug effects on transcription or protein synthesis. Twenty-four hours after viral transduction, cells were stimulated with $0.1 \mu \mathrm{M}$ forskolin in the presence of increasing concentrations of HT-0712 for $3 \mathrm{~h}$. Cells were then lysed with Britelite Plus reagent (Perkin Elmer) and luciferase activity was measured on an Envision 2104 Multilabel Reader (Perkin Elmer). Dose-Response curves were fitted using GraphPad Prism software. The experiments shown were repeated four times with similar results.

\section{Statistical Analysis}

In each experiment, the experimenter was unaware (blind) to the treatment of the subjects during training and testing. Induction of immediate early genes (IEG) was analyzed by two-factor ANOVA, and trace and delay conditioning by repeated measures ANOVA followed by contrast analysis (planned comparisons), the results of which are shown. Open-field behavior and acquisition in the MWM were analyzed by repeated measures ANOVA. Drug-treatment effects on target quadrant searching in the probe trials were analyzed by ANCOVA with treatment as between-group factor and probe-trial as covariate. This was followed by a $t$-test to determine whether search time in target quadrant differed from chance (25\%). All other data were analyzed by Student's unpaired $t$-test.

\section{RESULTS}

In previous studies, we showed that HT-0712 (Figure 1b) enhanced 1-day memory for a novel object recognition task in normal adult mice at doses of $0.05-0.2 \mathrm{mg} / \mathrm{kg}$ after intraperitoneal (i.p.) administration (Bourtchouladze et al, 2003). To establish if HT-0712 is effective when adminis- tered orally, we evaluated 1-day memory after cFC. Orally administered doses of 1 or $10 \mathrm{mg} / \mathrm{kg}$ yielded brain concentrations of $34 \mathrm{nM}$ and $433 \mathrm{nM}$, respectively, $1 \mathrm{~h}$ later (Figure 1a). When administered $30 \mathrm{~min}$ before $\mathrm{cFC}$ training, $1 \mathrm{mg} / \mathrm{kg}$ or $10 \mathrm{mg} / \mathrm{kg}$ of HT-0712 yielded 1-day memory scores significantly greater than vehicle-treated control animals $(P<0.001$ for $1 \mathrm{mg} / \mathrm{kg}$ and $P<0.01$ for $10 \mathrm{mg} / \mathrm{kg}$ of HT-0712). A lower dose of HT-0712 $(0.25 \mathrm{mg} / \mathrm{kg})$ had no effect (Figure 1c). Thus, HT-0712 potently facilitates contextual memory when administered orally at doses $1 \mathrm{mg} / \mathrm{kg}$ or above. The $1 \mathrm{mg} / \mathrm{kg}$ oral dose yielded brain exposures that were similar to those observed at a dose of $0.1 \mathrm{mg} / \mathrm{kg}$ given via intra-peritoneal injection $\left(\mathrm{C}_{\max }\right.$ p.o.: $17.7 \mathrm{ng} / \mathrm{g}$; i.p.: $7.2 \mathrm{ng} / \mathrm{g} ; \mathrm{t}_{1 / 2}$ p.o.: $0.65 \mathrm{~h}$, i.p.: $0.54 \mathrm{~h}$; AUC p.o.: $9.56 \mathrm{~h}{ }^{\star} \mathrm{ng} / \mathrm{ml}$, i.p.: $\left.6.11 \mathrm{~h}{ }^{\star} \mathrm{ng} / \mathrm{ml}\right)$. HT0712 was thus dosed i.p. in all of the following studies.

In studies of memory, drugs frequently are administered after training to separate their potential effects on sensorimotor systems or learning (acquisition) from memory formation per se (McGaugh and Petrinovich, 1965; McGaugh, 1966). Therefore, we evaluated the effects of post-training injection (i.p.) of HT-0712 on contextual memory (Figure 1d). HT-0712 administered $1 \mathrm{~h}$ after cFC training significantly enhanced 4 -day memory $(P<0.001)$. In contrast, HT-0712 was not effective after post-training injections (i.p.) of 3 or $6 \mathrm{~h}$ (data not shown). These data suggest a pharmacodynamic effect of HT-0712 for about $1 \mathrm{~h}$ after training. Importantly, HT-0712 had no effect on 1-day memory after five training trials of cFC (Figure 1d), which is sufficient in $\mathrm{C} 57 \mathrm{Bl} / 6$ mice to produce maximal 1-day memory. Hence, HT-0712 did not induce more memory. Rather, maximum memory was induced with less training.

HT-0712 did not affect sensorimotor responses to the stimuli used during cFC. We examined the effects of HT0712 on (i) nociception as a measure of perception and reaction to footshock and on (ii) open-field behavior as a measure of motor- and exploratory activity. HT-0712 did not increase nociception after i.p. administration (data not shown). Similarly, HT-0712 did not significantly affect locomotor activity or rearing in the open field (Figure 1e).

The $1 \mathrm{mg} / \mathrm{kg}$ p.o. dose yielded brain concentrations of $34 \mathrm{nM}$ HT-0712. To explore the relationship between the concentration of HT-0712 and its potency to facilitate CREB-mediated gene expression in neurons, we transduced cultured hippocampal neurons with adenovirus harboring a CRE-firefly luciferase reporter gene. To control for nonspecific effects of drug on transcription, mRNA stability, protein synthesis or efficiency of viral transduction, we included a Renila luciferase control gene from a U6 promoter in the same viral vector. Our adenovirus transduced almost $100 \%$ of cultured neurons, but had no effect on neuronal morphology (Figure 2b). We treated cultures with a low dose of the adenlyl cyclase activator forskolin, to mildly raise cAMP and drive relatively weak CRE-mediated gene expression, and tested the effect of various doses of HT-0712. We found that HT-0712 produced a large $\left(\mathrm{E}_{\max }=6.3\right.$-fold induction compared with vehicle) and potent $\left(\mathrm{EC}_{50}=257 \mathrm{nM}\right)$ increase in CREmediated gene expression in our mouse hippocampal cultures, but had no effect on the control gene (Figure 2c and d). Thus, HT-0712 increases neuronal CRE-mediated gene expression at concentrations similar to those in the brain after memory-enhancing doses (Figure 1). 


\begin{tabular}{|c|c|c|c|c|c|c|c|}
\hline target & substrate & assay & IC50 $(\mu \mathrm{M})$ & $\begin{array}{c}\text { Inhibition } \\
\text { (\% control) }\end{array}$ & selectivity & $\begin{array}{l}\mathrm{C}_{\text {[brain }} / 1 \mathrm{CC} 50 \\
1 \mathrm{mg} / \mathrm{kg} \text { p.o. }\end{array}$ & $\begin{array}{r}C_{\text {[brain/ }} / \mathrm{lC} 50 \\
10 \mathrm{mg} / \mathrm{kg} \text { p.o. }\end{array}$ \\
\hline PDE $4 \mathrm{~d} 3$ & CAMP & TR-FRET & 0.15 & - & - & 0.2 & $2.9 x$ \\
\hline PDE1b & CAMP & TR-FRET & $>75$ & - & $>500$ fold & $<0.01$ & $<0.01$ \\
\hline PDE2a & CAMP & TR-FRET & 3.83 & - & 25 fold & $<0.01$ & 0.1 \\
\hline PDE3a & CAMP & TR-FRET & $>75$ & - & $>500$ fold & $<0.01$ & $<0.01$ \\
\hline PDE10a & CAMP & TR-FRET & $>75$ & - & $>500$ fold & $<0.01$ & $<0.01$ \\
\hline Rolipram & mouse brain & binding & - & 98 & - & - & - \\
\hline
\end{tabular}

b
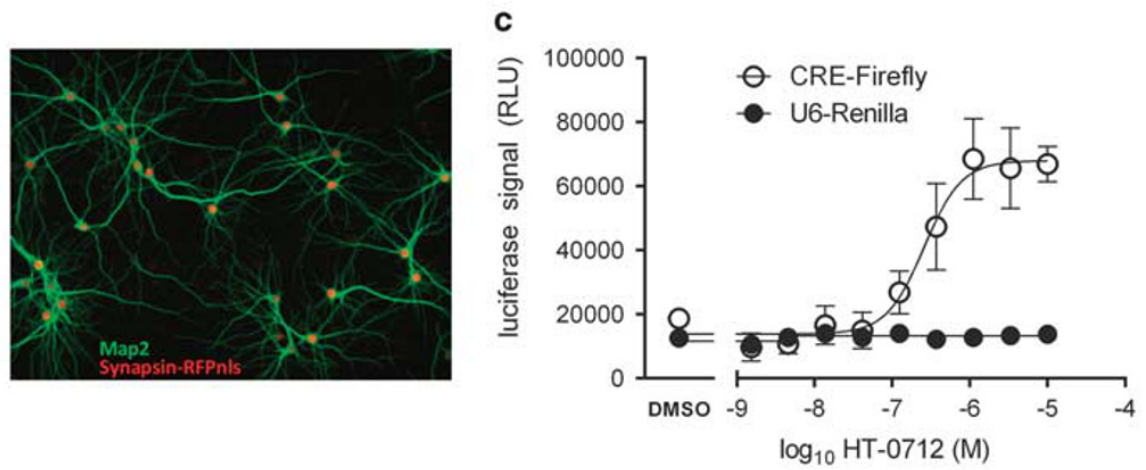

d

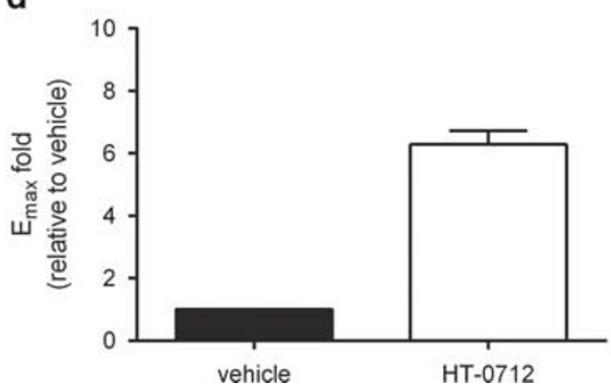

Figure 2 HT-07/2 facilitates CRE-mediated gene expression in hippocampal neurons. Drug effects on phosphodiesterase activity and reporter-gene expression from a CRE-regulated promoter in primary neurons. (a) Effect of HT-07/2 on enzymatic activity of PDE4d3 and the cAMP hydrolyzing phosphodiesterases PDEIb, PDE2a, PDE3a, and PDEIO. HT-07/2 potently blocked PDE4d3 but had little or no effect on the activity of other phosphodiesterases. HT-07/2 blocked binding of the PDE4 inhibitor Rolipram in mouse brain extracts by $98 \%$. (b) Hippocampal neurons in culture transduced with adenovirus expressing nuclear localized RFP (red) from a synapsin I promoter to label neuronal nuclei. Staining with MAP2 (green) revealed that adenoviral gene expression occurred in almost 100\% of neurons without obvious effects on neuronal morphology. (c) HT-07/2 dose dependently enhanced Forskolin stimulation of CRE-mediated expression of Firefly luciferase, but had no effect on U6 promoter driven expression of luciferase from a Renilla reniformis. (d) Maximal response in the presence of HT-07 I2. Mean \pm SD of four experiments are shown.

Interestingly, the potency of HT-0712 observed in our neuronal culture system was in line with its potency to block PDE4d3 in vitro $\left(\mathrm{IC}_{50}=0.15 \mu \mathrm{M}\right.$, Figure 2a). HT-0712 was inactive when tested against the dual-specific (cAMP/ cGMP) phosphodiesterases PDE1b, PDE3a, and PDE10a. Some inhibition of PDE2a catalytic activity was observed in vitro $(\mathrm{IC} 50=3.83 \mu \mathrm{M})$. However, this was not considered physiologically relevant because memory enhancement occurred at brain concentrations $(34 \mathrm{nM})$ that were too low to cause significant inhibition of PDE2a. We tested the effects of a high dose of HT-0712 $(10 \mu \mathrm{M})$ in a panel of receptor binding assays and found no physiologically relevant interactions. HT-0712 did not block ligand binding at dopamine receptors (D1, D2, D4.4, D5), adrenergic receptors $(\mathrm{A} 1, \mathrm{~A} 2 \mathrm{a}, \mathrm{B} 1, \mathrm{~B} 2)$, ionotrophic glutamate receptors (NMDA, AMPA, KA), gamma-aminobutyric acid receptors $\left(\mathrm{GABA}_{A}, \mathrm{GABA}_{\mathrm{B}}\right)$, histamine receptors $(\mathrm{H} 1, \mathrm{H} 2$, $\mathrm{H} 3$ ), and at the neurotransmitter transporters (DAT, NET, SERT). Thus, HT-0712 inhibited PDE4 specifically.

Next, we tested $\mathrm{cFC}$ in aged $\mathrm{C} 57 \mathrm{Bl} / 6$ mice and found that LTM was impaired, whereas STM remained unaffected (Figure 3a). Young and aged mice were trained with five 
a
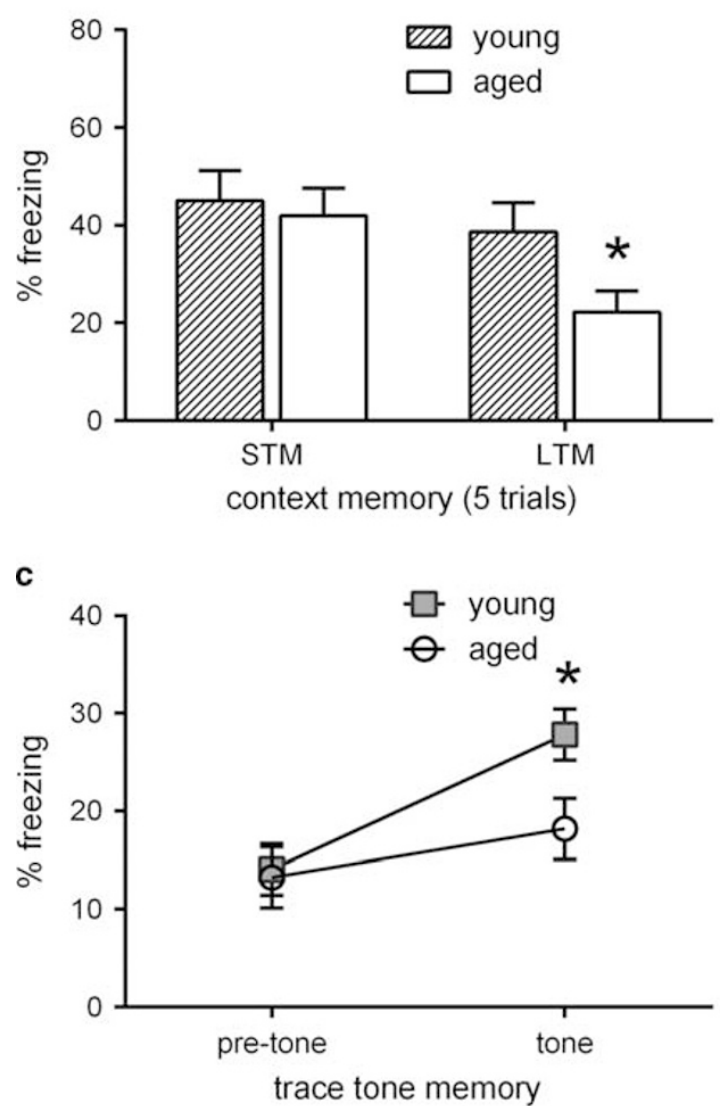

$\mathrm{e}_{1}$

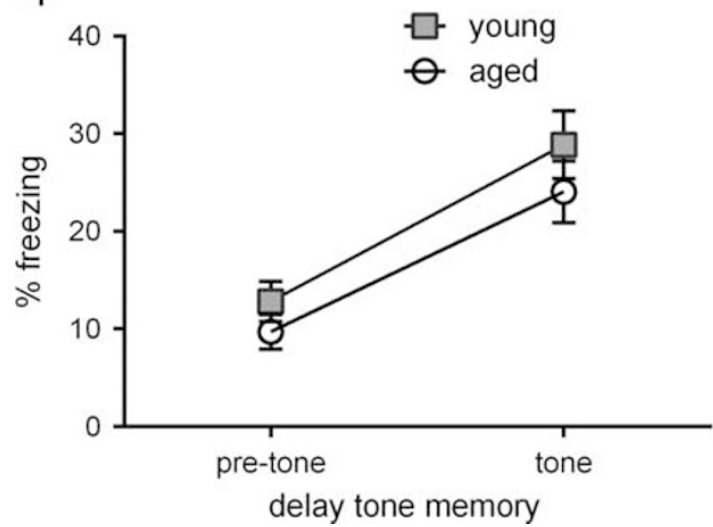

b

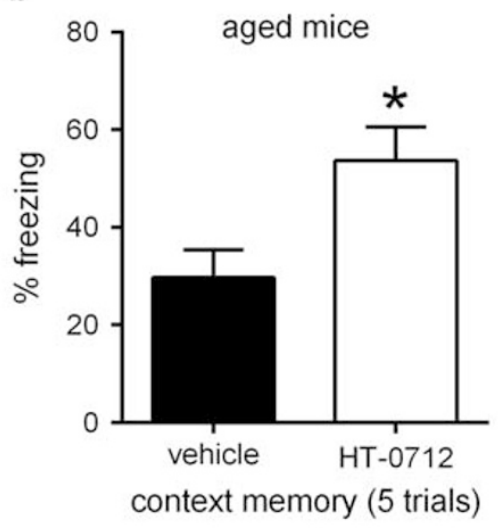

d

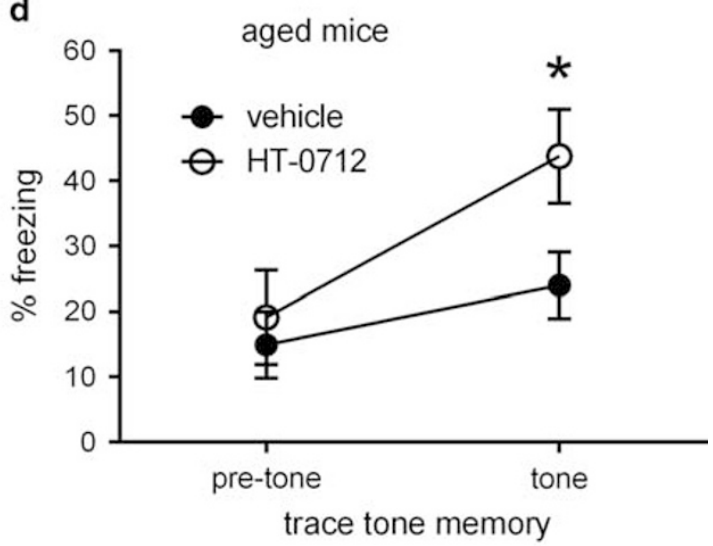

$\mathrm{e}_{2}$

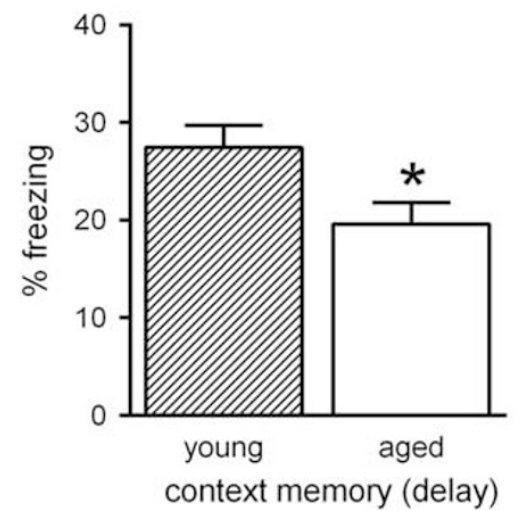

Figure 3 Effect of HT-07/2 on contextual and temporal memory in aged C57B//6 mice. Age and drug effects on contextual and temporal memory. (a) Contextual fear conditioning in aged mice. Mice were trained and tested $30 \mathrm{~min}$ (STM) or $24 \mathrm{~h}$ (LTM) later. Contextual LTM was significantly impaired in aged mice, but was not affected. STM: $n=9$, LTM: $n=12$. (b) Effect of HT-07I 2 on contextual LTM in aged mice. HT-07 I 2 significantly enhanced contextual memory compared with vehicle. Vehicle: $n=16, H T-07 \mid 2: n=19$. (c) Trace fear conditioning with a I 5 s trace interval. Only young mice froze on tone CS presentation, whereas freezing before onset of tone (preCS) was similar between young and aged mice. Young: $n=62$, Aged: $n=44$. (d) Effect of HT-07I2 on trace fear memory. Aged mice treated with HT-07I2, but not vehicle control injected mice, froze on tone CS presentation. Vehicle: $n=24, \mathrm{HT}-07 \mathrm{I}$ : $n=12 . e_{1}$ ) Delay fear conditioning. Young and aged mice equally froze to the tone CS presented $22 \mathrm{~h}$ after training. Young: $n=45$, Aged: $n=44$. $e_{2}$ ) Contextual memory tested $24 \mathrm{~h}$ after training $\left(2 \mathrm{~h}\right.$ after the tone-test in $\mathrm{e}_{\mathrm{I}}$ ) was reduced in aged mice. Mean \pm SEM are shown. Significant differences from young mice or vehicle control are indicated by an asterisk (*).

CS-US trials, yielding maximal 1-day memory in young mice. Aged mice had significantly impaired LTM $24 \mathrm{~h}$ after cFC compared with young mice $(P<0.05)$. In contrast, short-term memory measured 30 min after training was normal in separate groups of aged and young animals run in parallel. We then asked whether these age-related memory deficits were rescued by HT-0712. Indeed, when mice were treated with $0.1 \mathrm{mg} / \mathrm{kg}$ HT-0712 (dosed i.p.) or vehicle alone and trained in the cFC task, HT-0712 improved 1-day memory observed in aged $\mathrm{C} 57 \mathrm{Bl} / 6$ mice 
(Figure 3b). HT-0712-injected aged mice froze significantly more in the retention trial than vehicle-injected aged mice $(P<0.05)$, and their freezing levels were comparable to those observed in young mice 1-day after $\mathrm{cFC}$ training with five CS-US trials.

We then compared memory for tFC between young and aged $\mathrm{C} 57 \mathrm{Bl} / 6$ mice (3-and 20 -month old, respectively). We used a trace interval of $15 \mathrm{~s}$ and quantified memory retention of tone (the CS) 1-day after training (Figure 3c). There was a significant trial by age interaction $(P<0.05)$. Planned pairwise comparisons between groups revealed that aged C57BL/6 mice froze to the CS (tone) 1 day after training significantly less than young mice $(P<0.05)$. PreCS freezing was not significantly different, however, between aged and young mice. Further, freezing to CS (tone) was greater than that to preCS in young mice $(P<0.001)$ but not in aged mice. Thus, 1 day after training, aged $C 57 \mathrm{Bl} / 6$ mice could not remember that tone had been paired with footshock. To examine whether aged mice can learn a CS-US association in an easier version of $\mathrm{tFC}$, we shortened the trace interval to $5 \mathrm{~s}$. Here again, aged $\mathrm{C} 57 \mathrm{Bl} / 6$ mice froze to tone significantly less than young mice, and they did not associate the CS and US (data not shown).

Next, we tested the effect of HT-0712 on tFC in aged mice (Figure 3d). When dosed at $0.1 \mathrm{mg} / \mathrm{kg}$ i.p., we found a significant trial-by-drug interaction $(P<0.05)$. One-day memory to tone (CS) in HT-0712-injected mice was significantly greater than that in vehicle-injected mice $(P<0.05)$, and only the drug-treated mice increased their freezing response between preCS and CS $(P=0.22)$. We also enhanced 1-day memory after tFC using a dose of $0.15 \mathrm{mg} / \mathrm{kg}$ i.p. (data not shown). In this assay, aged mice treated with HT-0712 performed significantly better than aged mice treated with vehicle.

Memory formation after $\mathrm{CFC}$ and tFC requires hippocampal function (McEchron et al, 1998; Clark and Squire, 1998). Delay FC (dFC), in contrast, does not require hippocampal function and is normal in patients and experimental animals with hippocampal damage (Phillips and LeDoux, 1992; Clark and Squire, 1998; McEchron et al, 1998). We evaluated aged C57Bl/6 mice in $\mathrm{dFC}$ to assess the impact of age on a non-hippocampal-dependent form of fear conditioning. Freezing to tone $22 \mathrm{~h}$ after training did not differ between young and aged mice, and freezing to CS was greater than that to preCS in both young and aged mice (Figure 3e). As an important control, we measured 1-day memory of $\mathrm{cFC}$ in the same animals $(2 \mathrm{~h}$ after testing to tone) and found that despite normal dFC in aged animals, cFC was impaired $(P<0.05)$. These data indicate that the effects of aging are specific to hippocampus-dependent forms of fear conditioning, so we focused on the hippocampus when investigating gene expression changes associated with memory.

In concordance with previous results in memory-impaired aged rats (Brightwell et al, 2004), we found reduced levels of hippocampal Creb mRNA and protein in the aged $\mathrm{C} 57 \mathrm{Bl} / 6$ mice (data not shown), suggesting that activation of $C R E B$ target genes by behavioral training could be affected by aging. To further evaluate this possibility, we trained young and aged mice in tFC task and measured mRNA levels of four CREB-regulated genes by quantitative realtime PCR (qPCR).
Compared with naive mice, cFos mRNA was elevated $1 \mathrm{~h}$ after training in both young and aged mice (Figure 4a). Two-way ANOVA revealed a significant training $\times$ age interaction $(P<0.0001)$, however, indicating that induction of $c$ Fos in aged mice was lower than that in young mice. A similar pattern of expression was observed with Zif268 (Figure 4b). Compared with naive mice, $B d n f$ mRNA also was elevated $1 \mathrm{~h}$ after training in young mice (Figure $4 \mathrm{c}$ ). The effect of age on this training-induced increase in mRNA expression was stronger than for cFos and Zif268. Bdnf mRNA levels after training were significantly lower in aged mice than in young mice $(P<0.001)$ and appeared not to be induced at all in aged mice $(P=0.70)$. Expression of $N r 4 a 1$ (Ngfi-b/Nur77), another IEG reported to be induced by fear conditioning (Malkani and Rosen, 2000; von Hertzen and Giese, 2005) also was increased $1 \mathrm{~h}$ after tFC training (Figure $4 \mathrm{~d}$ ). In contrast to the first three examples, however, age had no effect on this training-induced expression, revealing that expression of some plasticity genes may be spared by aging.

HT-0712 facilitated the age-associated decreases in training-induced gene expression for $c F o s$, Zif268, and Bdnf (Figure 4e-g). Aged mice were dosed (i.p.) with either $0.1 \mathrm{mg} / \mathrm{kg} \mathrm{HT}-0712$ or vehicle, subjected to $15 \mathrm{~s} \mathrm{tFC}$, and mRNA was measured $1 \mathrm{~h}$ later. Expression of $c F o s$ $(P<0.001)$, Zif268 $(p<0.05)$, and $B d n f(P<0.01)$ were significantly increased in the hippocampus of trace-conditioned aged mice. In contrast, no significant effect of HT0712 was seen for Nr4al (Figure $4 \mathrm{~h}$ ). Taken together, these data indicate that HT-0712 in vivo facilitates the expression of CREB-regulated genes, which are decreased with age.

Finally, we asked if the effects of HT-0712 on fear conditioning generalized to other forms of hippocampusdependent memory, and tested aged mice with and without drug in the hidden platform version of the Morris water maze. Aged C57Bl/6 mice were previously reported to be impaired in this test of hippocampus-dependent spatial memory (Murphy et al, 2006; von Bohlen und Halbach et al, 2006). We trained aged $C 57 \mathrm{Bl} / 6$ mice for four trials per day, each of 5 days over a 3-week period. Animals were dosed (i.p.) with either $0.15 \mathrm{mg} / \mathrm{kg}$ HT-0712 or vehicle once daily 20 min prior to the first trial. During acquisition, average daily escape latency and swimming path length did not differ between drug and vehicle-treated groups, indicating that escape strategy per se was not affected by HT-0712 (Figure 5a and b). Furthermore, no significant difference was found when escape latencies and swimming path length in the first trial of each day were analyzed (Figure $5 \mathrm{c}$ and data not shown). However, analysis of searching in the target quadrant during probe trials given on days $3,5,10$, and 15 of training revealed a significant main effect of drug treatment (ANCOVA: $p<0.05$ ), indicating that HT-0712treated aged mice spent more time searching in the target quadrant than vehicle-treated mice (effect of time: $p<0.001$ ). Furthermore, drug-treated mice spent significantly more time searching in the target quadrant than expected by chance during the probe-trial given at the end of the second and third training week $(P<0.05$ for Day $10 ; P<0.005$ for Day 15; student's $t$-test $v s$ 25\%) (Figure $5 \mathrm{~d} 2$ ), whereas vehicle-treated mice did not. No effects of drug treatment were observed in probe trials on days 3 and 5 within the first week of training (Figure 5d1). 


\section{DISCUSSION}

Multiple studies have demonstrated detrimental effects of aging on CREB-dependent processes involved in long-term memory formation. Here, we have shown that $\mathrm{tFC}$-induced

a

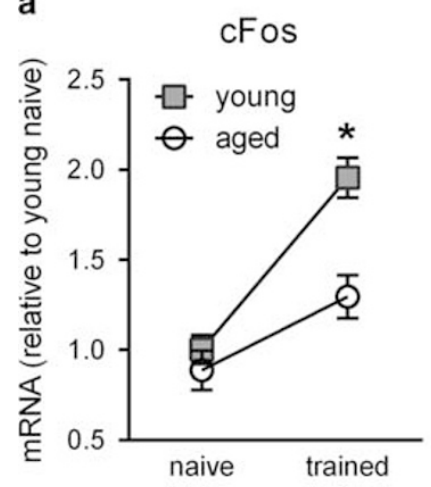

b

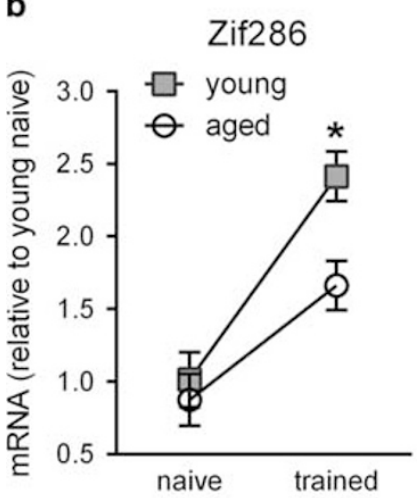

C

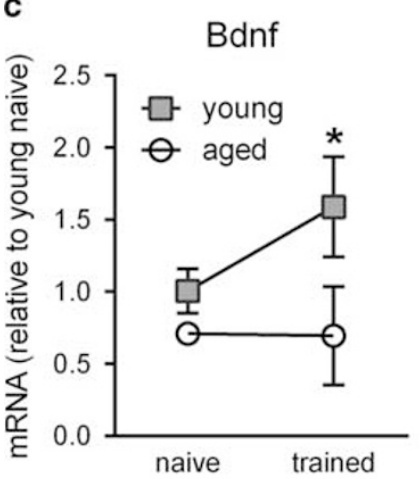

d

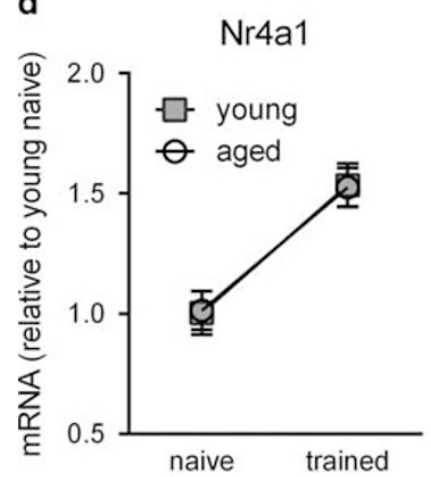

e

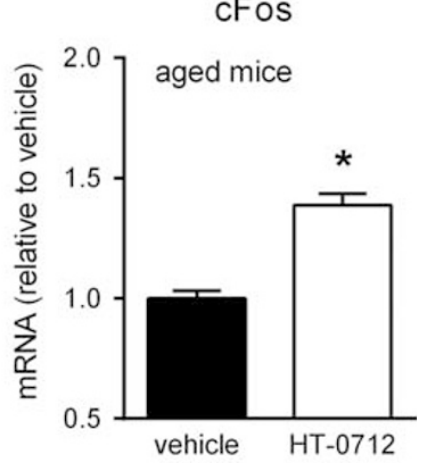

f

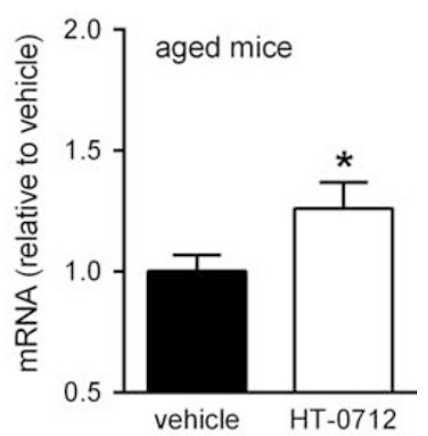

g

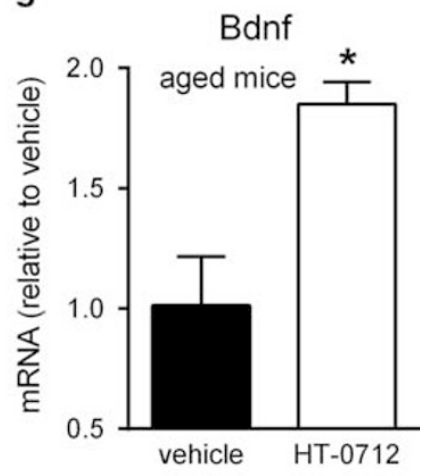

h

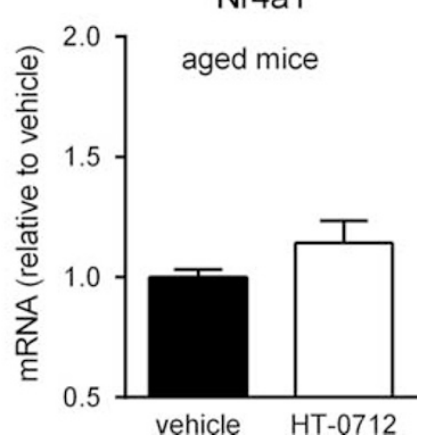

expression of CREB-dependent genes, $c$ Fos and Bdnf, were reduced and long-term memory formation was impaired in aged mice. In aged memory-impaired rats, hippocampal levels of CREB1 protein were found to be reduced when compared with young rats (Brightwell et al, 2004). Experience-dependent activation of CREB and its downstream targets is altered in aged mice (Porte et al, 2008) and rats (Monti et al, 2005; Countryman and Gold, 2007). Further, hippocampal mRNA expression of the adenyl cyclases AC1 and AC9 (Mons et al, 2004) and activation of protein kinase A (Karege et al, 2001) are reduced in the hippocampus of aged rodents. Interestingly, age-related changes in mRNA expression of CAMK4 and MAPK1, two kinases activating CREB by Ser133 phosphorylation, have been observed in human cortex (Lu et al, 2004; Lonze and Ginty, 2002). Transgenic expression of CREB protein (Mouravlev et al, 2006) or its activator CAMKIV (Fukushima et al, 2008) improves memory in aged mice. Thus, ageassociated memory impairment can be ameliorated by several molecular manipulations of the CREB pathway.

We have shown here that HT-0712 facilitates CREBmediated transcription in cultured neurons and blocks Pde 4 at concentrations in line with those found in the brains of young mice at systemic doses that enhance long-term memory formation. We found that an oral dose of $1 \mathrm{mg} / \mathrm{kg}$ HT-0712 yielded brain concentrations of $34 \mathrm{nM} 1 \mathrm{~h}$ later. Potent effects on CRE-mediated gene expression were observed with EC50 values of 257 nM. In enzymatic studies, HT-0712 blocked Pde4d3 with comparable potency (IC50 of $0.15 \mu \mathrm{M})$, and it was selective against other phosphodiesterases, receptor targets, and ion channels. In addition, HT0712 facilitated the expression of three CREB-dependent genes Zif268, cFos and, Bdnf in trace fear conditioned aged mice. Although we cannot be sure that HT-0712 entirely normalized CREB-mediated gene expression in aged mice because we did not directly compare gene expression changes in drug-treated young and aged mice, our results are consistent with a mode of action by which HT-0712 facilitates memory in aged mice via selective inhibition of Pde4d and enhancement of neuronal transcription. In previous studies, we used a pharmaco-genomic approach to show that HT-0712 facilitates long-term memory formation in mice heterozygous for mutation of CREBbinding protein (CBP), where a higher-than-normal dose

Figure 4 Effect of age and HT-07/2 on hippocampal immediate early gene expression. Age and drug effects on hippocampal cFos, Zif268, Bdnf, and Nr4al mRNA expression. (a-d) Quantitative real-time PCR analysis of immediate early gene induction by trace fear conditioning in young and aged C57B//6 mice. Hippocampal mRNA levels I h after trace fear conditioning are shown (normalized to young naive mice). cFos, Zif268, and Nr4al: $n=5$ per group, Bdnf: $n=5$ naïve, $n=6$ trained. Induction of cFos (a), Zif268 (b), and Bdnf (c) were altered in aged mice. There was no effect on the expression of $\mathrm{Nr} 4 \mathrm{al}$ ( (d). (e-h) Quantitative real-time PCR analysis of HT-07/2 effects on immediate early gene expression. Aged mice were treated with drug or vehicle 20 min prior to training. Hippocampal mRNA levels I $\mathrm{h}$ after training are shown (normalized to vehicle control treated mice). cFos (e), Zif268 (f), and Bdnf (g) mRNA levels were significantly higher in HT-07/2-treated mice. The effect on $\mathrm{Nr} 4 \mathrm{al}$ l expression was not significant (h). cFos: $n=5$, Bdnf: $n=4, N r 4 a l: n=5$. The mean \pm SD is shown. Significant differences from young mice $(a-d)$ or vehicle control injected aged mice (e-h) are indicated by an asterisk (*). 
a

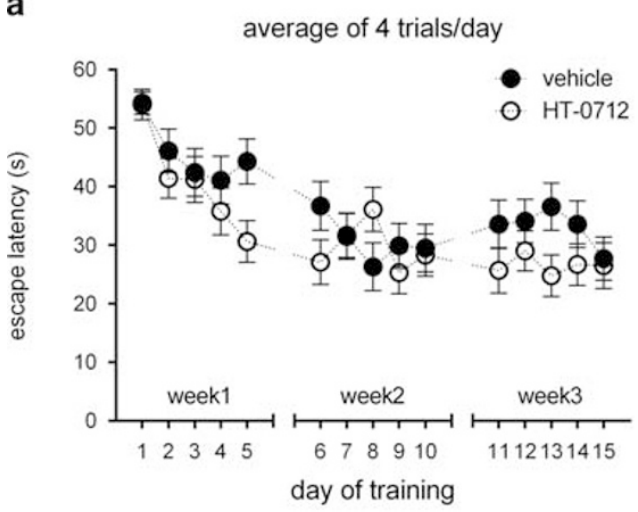

C

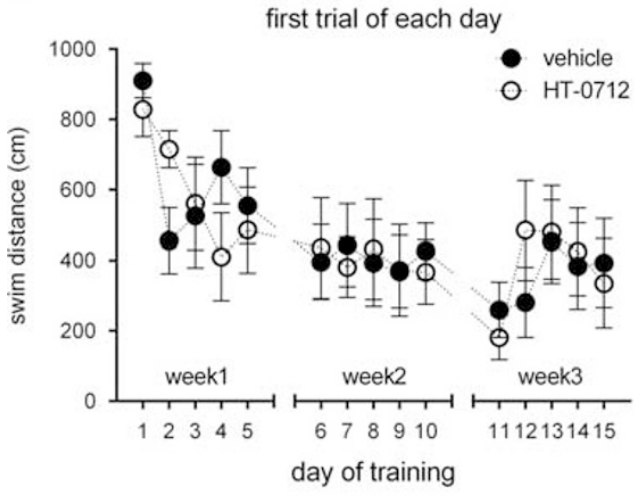

b

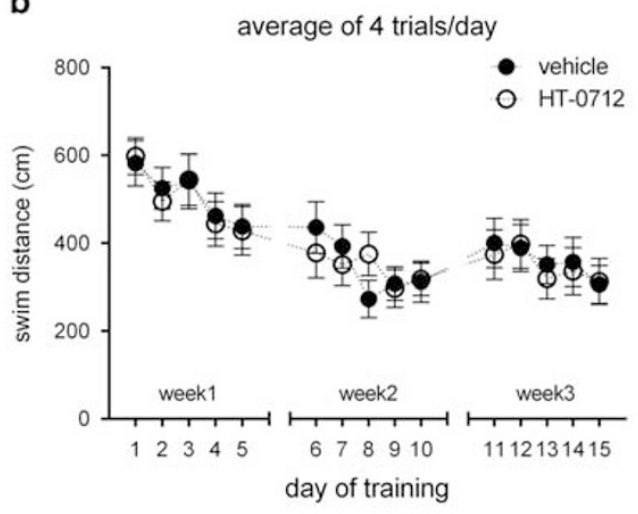

$d_{1}$

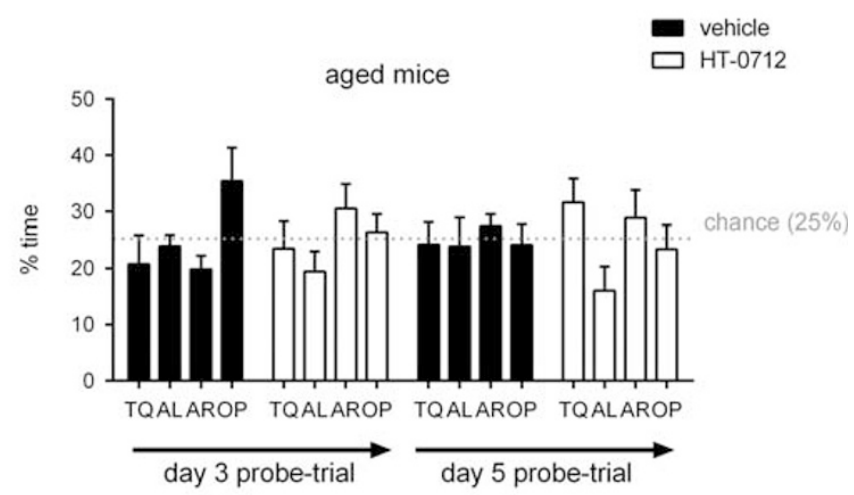

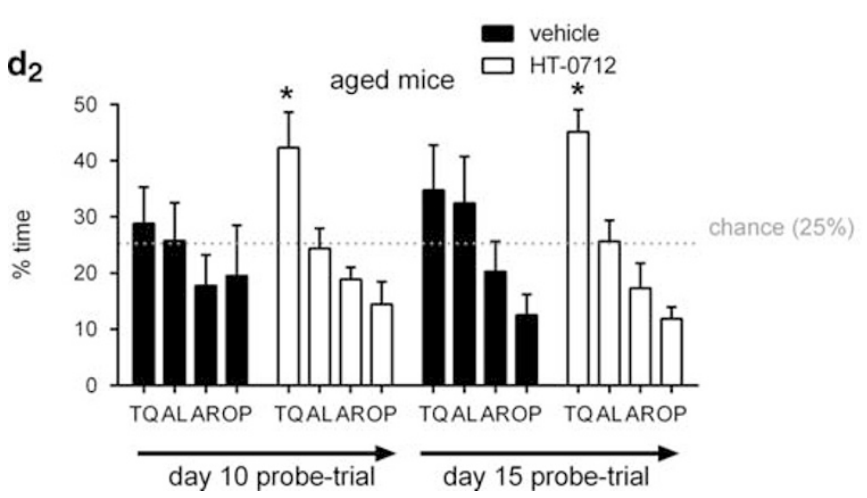

Figure $5 \mathrm{HT}-07 / 2$ improves spatial memory in aged mice. Effect of HT-07/2 on performance of aged mice in the hidden platform version of the Morris water maze. (a) HT-07/2 had no significant effect on the latency to find the platform on each day of the acquisition phase. Gaps in the graph correspond to 2-day breaks between weeks of training. (b) HT-07/2 dosed once daily 20 min prior to training had no effect on the path length of swimming until the platform was found. (c) HT-07/2 did not affect the path length of swimming in the first trial of each training day. ( $d_{1}$ ) Quadrant searching in probe trials on days 3 and 5. Neither vehicle nor HT-07I 2 dosed aged mice searched selectively in the target quadrant in the probe trials given during week I of training. $\left(d_{2}\right)$ Quadrant searching in probe trials on days 10 and 15 . Only HT-07/2 dosed aged mice searched selectively in the target quadrant in probe trials given at the end of week 2 and week 3 of training. TQ: target quadrant. AL: adjacent-left to target quadrant. AR: adjacent-right to target quadrant. OP: opposite to target quadrant. Vehicle: $n=7, \mathrm{HT}-0712: n=8$. The mean \pm SEM is shown. Asterisk (*) indicates significant difference for time spent searching in TQ vs chance $(25 \%)$

was required to enhance long-term memory formation (Bourtchouladze et al, 2003). Together with the data presented here, these findings provide evidence for a CBP/ CREB-dependent mechanism of action for HT-0712.

Importantly, the age-related deficits in context and trace fear memory shown here paralleled those observed after siRNA knockout of CREB in the hippocampus of C57Bl/6 mice (Peters et al, 2009). The trace conditioning provides an excellent model for exploring drug effects on attentive phenomena and temporal memory processing in experimental aged animals. The imposition of a short interval between the tone CS and shock US in trace conditioning increases the complexity of the learning task, rendering it dependent on the hippocampus (McEchron et al, 1998). As the 'trace' increases, the memory becomes gradually worse. Human amnesiacs, aged people, and aged animals are 
especially deficient in trace conditioning (McGlincheyBerroth et al, 1997; Clark and Squire, 1998; McEchron et al, 2004). Performance in the delay tone fear conditioning requires similar sensory motor abilities, but it does not dependent on the hippocampus (Phillips and LeDoux, 1992; McEchron et al, 1998). We found that delay tone memory was normal in aged $\mathrm{C} 57 \mathrm{Bl} / 6$ mice, whereas context memory was impaired in the same animals. Thus, the deficits in memory for trace and cFC did not result from sensory (hearing, shock perception) or motor (freezing) inability to perform the memory test. HT-0712 facilitated context and trace memory, indicating that it improves contextual as well as temporally spaced associations in aged mice. In young mice, HT-0712 affected consolidation of contextual memory when dosed before or shortly after training but had no effect on measures of locomotor activity or shock perception.

HT-0712, but not vehicle, treated aged mice searched selectively in the probe trials on days 10 and 15 of the Morris water maze test of spatial memory. However, HT0712 did not affect escape latencies or path length during acquisition. This indicates that HT-0712 did not affect motivation, motor coordination, or visual acuity as both vehicle and drug-treated aged mice learned to find and climb onto the platform. However, escape latency and path length are not good measures of hippocampal function, because mice can use alternative hippocampus-independent strategies to locate the platform. Aged $\mathrm{C} 57 \mathrm{Bl} / 6$ mice perform equally to young mice in the path length measure of performance in the water maze, but they do not search selectively in probe trials (von Bohlen und Halbach et al, 2006). In addition, mutant mice with altered activation of hippocampal CREB and synaptic plasticity acquire the task normally, but they do not search selectively (Peters et al, 2003). The specific effects of HT-0712 on probe-trial performance are thus consistent with a drug effect on hippocampal function. Our findings also suggest that HT0712 dosed repeatedly (once daily) augments memory, although further studies are required to better understand the effects of repeated administration on memory and CREB activation in aged mice.

Theoretically, it is possible that deficient working memory could have impaired the ability of aged mice to bridge the temporal gap between CS and US during trace conditioning. Trace fear conditioning is blocked by inhibition of the medial prefrontal cortex, which is engaged during temporal memory encoding (Kesner, 2005; Blum et al, 2006; Gilmartin and Helmstetter, 2010). Thus, HT0712 could have affected temporal memory in aged mice via facilitation of prefrontal cAMP signaling and working memory. Because we did not test the effect of HT-0712 on acquisition and short-term memory in the trace fear conditioning task, we cannot conclude that the observed drug effect was specific to memory consolidation. However, HT-0712 injected $1 \mathrm{~h}$ after contextual training improved long-term memory in young mice and such effect is consistent with enhanced consolidation (McGaugh and Petrinovich, 1965; McGaugh, 1966). Future studies should thus address the question if HT-0712 dosed systemically affects long-term memory specifically, or if the drug has additional beneficial effects on working memory.

Our results extend previous studies demonstrating the effect of HT-0712 in a mouse model of Rubinstein-Taybi syndrome (Bourtchouladze et al, 2003), and in stroke rehabilitation in the rat (MacDonald et al, 2007). Thus, HT0712 ameliorates deficits in rodent models of intellectual disability, aging, and motor recovery. HT-0712 may be a suitable treatment for a variety of conditions benefiting from enhanced plasticity, including memory deficits in human patients with AAMI or amnestic MCI.

\section{FUNDING AND DISCLOSURE}

This work was supported by Dart Neuroscience and in part by The Institute for the Study of Aging (ISOA, now Alzheimer's Drug Discovery Foundation). All authors are current or past employees of Dart Neuroscience.

\section{ACKNOWLEDGEMENTS}

This manuscript is published in memory of Rusiko Bourtchouladze who conceptualized many of the studies shown here and was a mentor to MP. We thank Wei Jiang and Jennifer Lapira for conducting neuronal CRE-luci studies; Eben Massari, Thomas Glaza, Zachary Yoder, and Kristen Sebring for selectivity data; Andrew Morse for pharmacokinetic studies; and Steven de Belle for critical comments on the manuscript. Author contributions: MP designed research, conducted research, and wrote the manuscript; $\mathrm{MB}$, JS, and DW conducted research; RS and TT designed research and edited the manuscript.

\section{REFERENCES}

Bach ME, Barad M, Son H, Zhuo M, Lu YF, Shih R et al (1999). Age-related defects in spatial memory are correlated with defects in the late phase of hippocampal long-term potentiation in vitro and are attenuated by drugs that enhance the cAMP signaling pathway. Proc Natl Acad Sci USA 96: 5280-5285.

Barad M, Bourtchouladze R, Winder DG, Golan H, Kandel E (1998). Rolipram, a type IV-specific phosphodiesterase inhibitor, facilitates the establishment of long-lasting long-term potentiation and improves memory. Proc Natl Acad Sci USA 95: $15020-15025$.

Barnes CA (1988). Aging and the physiology of spatial memory. Neurobiol Aging 9: 563-568.

Blum S, Hebert AE, Dash PK (2006). A role for the prefrontal cortex in recall of recent and remote memories. Neuroreport 17: 341-344.

Bourtchouladze R, Lidge R, Catapano R, Stanley J, Gossweiler S, Romashko D et al (2003). A mouse model of Rubinstein-Taybi syndrome: defective long-term memory is ameliorated by inhibitors of phosphodiesterase 4. Proc Natl Acad Sci USA 100: 10518-10522.

Bourtchuladze R, Frenguelli B, Blendy J, Cioffi D, Schutz G, Silva AJ (1994). Deficient long-term memory in mice with a targeted mutation of the cAMP-responsive element-binding protein. Cell 79: $59-68$.

Brightwell JJ, Gallagher M, Colombo PJ (2004). Hippocampal CREB1 but not CREB2 is decreased in aged rats with spatial memory impairments. Neurobiol Learn Mem 81: 19-26.

Clark RE, Squire LR (1998). Classical conditioning and brain systems: the role of awareness. Science 280: 77-81.

Countryman RA, Gold PE (2007). Rapid forgetting of social transmission of food preferences in aged rats: relationship to hippocampal CREB activation. Learn Mem 14: 350-358. 
Fukushima H, Maeda R, Suzuki R, Suzuki A, Nomoto M, Toyoda H et al (2008). Upregulation of calcium/calmodulin-dependent protein kinase IV improves memory formation and rescues memory loss with aging. J Neurosci 28: 9910-9919.

Gallagher M, Pelleymounter MA (1988). Spatial learning deficits in old rats: a model for memory decline in the aged. Neurobiol Aging 9: 549-556.

Gilmartin MR, Helmstetter FJ (2010). Trace and contextual fear conditioning require neural activity and NMDA receptordependent transmission in the medial prefrontal cortex. Learn Mem 17: 289-296.

Hedden T, Gabrieli JD (2004). Insights into the ageing mind: a view from cognitive neuroscience. Nat Rev Neurosci 5: 87-96.

Karege F, Lambercy C, Schwald M, Steimer T, Cisse M (2001). Differential changes of cAMP-dependent protein kinase activity and $3 \mathrm{H}$-cAMP binding sites in rat hippocampus during maturation and aging. Neurosci Lett 315: 89-92.

Kesner RP (2005). Temporal processing of information: the role of the medial prefrontal cortex and hippocampus: theoretical comment on Gilmartin and McEchron (2005). Behav Neurosci 119: $1705-1709$.

Lonze BE, Ginty DD (2002). Function and regulation of CREB family transcription factors in the nervous system. Neuron 35: 605-623.

Lu T, Pan Y, Kao SY, Li C, Kohane I, Chan J et al (2004). Gene regulation and DNA damage in the ageing human brain. Nature 429: 883-891.

MacDonald E, Van der Lee H, Pocock D, Cole C, Thomas N, VandenBerg PM et al (2007). A novel phosphodiesterase type 4 inhibitor, HT-0712, enhances rehabilitation-dependent motor recovery and cortical reorganization after focal cortical ischemia. Neurorehabil Neural Repair 21: 486-496.

Malkani S, Rosen JB (2000). Induction of NGFI-B mRNA following contextual fear conditioning and its blockade by diazepam. Brain Res Mol Brain Res 80: 153-165.

McEchron MD, Bouwmeester H, Tseng W, Weiss C, Disterhoft JF (1998). Hippocampectomy disrupts auditory trace fear conditioning and contextual fear conditioning in the rat. Hippocampus 8: 638-646.

McEchron MD, Cheng AY, Gilmartin MR (2004). Trace fear conditioning is reduced in the aging rat. Neurobiol Learn Mem 82: 71-76.

McGaugh JL, Petrinovich LF (1965). Effects of drugs on learning and memory. Int Rev Neurobiol 8: 139-196.

McGaugh JL (1966). Time-dependent processes in memory storage. Science 153: 1351-1358.

McGlinchey-Berroth R, Carrillo MC, Gabrieli JD, Brawn CM, Disterhoft JF (1997). Impaired trace eyeblink conditioning in bilateral, medial-temporal lobe amnesia. Behav Neurosci 111 873-882.

Mons N, Segu L, Nogues X, Buhot MC (2004). Effects of age and spatial learning on adenylyl cyclase mRNA expression in the mouse hippocampus. Neurobiol Aging 25: 1095-1106.

Monti B, Berteotti C, Contestabile A (2005). Dysregulation of memoryrelated proteins in the hippocampus of aged rats and their relation with cognitive impairment. Hippocampus 15: 1041-1049.

Monti B, Berteotti C, Contestabile A (2006). Subchronic rolipram delivery activates hippocampal CREB and arc, enhances retention and slows down extinction of conditioned fear. Neuropsychopharmacology 31: 278-286.

Mouravlev A, Dunning J, Young D, During MJ (2006). Somatic gene transfer of cAMP response element-binding protein attenuates memory impairment in aging rats. Proc Natl Acad Sci USA 103: 4705-4710.

Murphy GG, Rahnama NP, Silva AJ (2006). Investigation of agerelated cognitive decline using mice as a model system: behavioral correlates. Am J Geriatr Psychiatry 14: 1004-1011.

Peters M, Mizuno K, Ris L, Angelo M, Godaux E, Giese KP (2003). Loss of $\mathrm{Ca} 2+/$ calmodulin kinase kinase beta affects the formation of some, but not all, types of hippocampus-dependent long-term memory. J Neurosci 23: 9752-9760.

Peters M, Bletsch M, Catapano R, Zhang X, Tully T, Bourtchouladze R (2009). RNA interference in hippocampus demonstrates opposing roles for CREB and PP1alpha in contextual and temporal long-term memory. Genes Brain Behav 8: 320-329.

Phillips RG, LeDoux JE (1992). Differential contribution of amygdala and hippocampus to cued and contextual fear conditioning. Behav Neurosci 106: 274-285.

Porte Y, Buhot MC, Mons N (2008). Alteration of CREB phosphorylation and spatial memory deficits in aged $129 \mathrm{~T} 2 / \mathrm{Sv}$ mice. Neurobiol Aging 29: 1533-1546.

Rapp PR, Rosenberg RA, Gallagher M (1987). An evaluation of spatial information processing in aged rats. Behav Neurosci 101: 3-12.

Simon SS, Yokomizo JE, Bottino CM (2012). Cognitive intervention in amnestic Mild Cognitive Impairment: a systematic review. Neurosci Biobehav Rev 36: 1163-1178.

Tully T, Bourtchouladze R, Scott R, Tallman J (2003). Targeting the CREB pathway for memory enhancers. Nat Rev Drug Discov 2: 267-277.

von Bohlen und Halbach O, Zacher C, Gass P, Unsicker K (2006). Age-related alterations in hippocampal spines and deficiencies in spatial memory in mice. J Neurosci Res 83: 525-531.

von Hertzen LS, Giese KP (2005). Memory reconsolidation engages only a subset of immediate-early genes induced during consolidation. J Neurosci 25: 1935-1942. 